\title{
When Appreciating Nature Makes One Care Less for Human Beings: The Role of Belief in Just Nature in Helping Victims of Natural Disasters
}

\author{
Adrian Wojcik • Aleksandra Cislak
}

Published online: 20 July 2013

(C) The Author(s) 2013. This article is published with open access at Springerlink.com

\begin{abstract}
The concept that nature is just and that it can act against its perpetrators is widespread among environmentalists. In the research presented, we show the consequences of sharing just-nature beliefs for reactions toward victims of natural catastrophes. A preliminary qualitative analysis of environmentalist discourse related to victims of Fukushima Daiichi nuclear disaster caused by a tsunami showed that just-nature beliefs were used to justify the Japanese tragedy. In the following three quantitative studies, we demonstrate that the belief in just-nature is related to a diminished tendency to help human beings who suffered from natural catastrophes. Two correlation studies conducted directly after the earthquake in Japan in 2011 on members of ecological organizations $(N=183)$ and undergraduates $(N=123)$ showed that just-nature beliefs result in a tendency to help by giving donations for reducing the consequences of nature rather than for human victims of the tragedy. The results were replicated in a correlation study of undergraduates $(N=153)$ conducted after Hurricane Sandy.
\end{abstract}

Keywords Belief in just nature $\cdot$ Helping $\cdot$ Money donation $\cdot$ Natural disasters

Great natural disasters elicit immediate worldwide interest and worldwide media coverage that is often followed by international aid. A significant part of tangible support offered to the victims often comes from organizations raising funds among ordinary citizens (Harvey, Stoddard, Harmer, \& Taylor, 2010). It is estimated that

\footnotetext{
A. Wojcik $(\bowtie)$

Faculty of Psychology, University of Finance and Management in Warsaw, Pawia

55, 01-030 Warsaw, Poland

e-mail: awojcik@uw.edu.pl

A. Cislak

Faculty of Psychology, University of Social Sciences and Humanities, Warsaw, Poland
} 
the private funding in response to humanitarian crises in 2011 totaled US\$4.6 billion. It is also estimated that from 50 to $60 \%$ of humanitarian aid is donated for the emergency responses (Poole \& Walmsley, 2012). At the same time, donating money usually is the only opportunity for those ordinary citizens coming from different parts of the world to declare one's solidarity with the victims and to help them in any way. The individual willingness to help the disaster victims depends on the attribution of responsibility for the harm and the perception of the victims (Zagefka, Noor, Brown, Randsley de Moura, \& Hopthrow, 2011). For example, people are more helpful to those whom they perceive as similar to themselves, both in their more frequent intervention in emergencies (West, Whitney, \& Schnedler, 1975) and in their greater willingness to donate money (Bryan \& Test, 1967). People are also more willing to help those whose need for help results from causes beyond their control rather than those who could have taken the necessary precautions to avoid misfortune (Ickes \& Kidd, 1976; Meyer \& Mulherin, 1980; Piliavin, Rodin, \& Piliavin, 1969; Weiner, 1980).

The tendency to attribute responsibility to the victim may stem from a more general belief in a just world (Lerner, 1980; Lerner \& Miller, 1978). People sharing the just-world view tend to perceive the world as the place in which both noble and wicked deeds are duly paid back as opposed to the unjust or the random world (Furnham, 2003). As a consequence, the tendency to alleviate the suffering of others may be inhibited among those who believe that generally one gets what one deserves. As innocent victims may threaten the belief in a just world, those whose beliefs are threatened consequently distance themselves from the victims (Hafer, 2000), which in turn may inhibit their willingness to help the victims. In the field of humanitarian aid, Skitka (1999) showed that individual tendencies to help the victims of natural disasters depend on political beliefs. While liberals are prone to help the victims of natural disasters regardless of attribution of responsibility, the decisions of conservatives are based on the perceived responsibility of victims. Helping the victims of natural disasters may also serve as a means to restore threatened in-group identity. When in-group identity is threatened, people tend to engage in helping out-groups in the domain that pertains to the in-group identity (van Leeuwen, 2007). In general, people are more willing to donate to the victims of natural disasters than to the victims of disasters directly provoked by humans, as the victims of natural disasters are blamed less (Zagefka et al., 2011).

However, even the disastrous effects of natural catastrophes on human beings may be perceived as resulting from human activity. Just as people may tend to perceive the social world as just and therefore tend to blame the victims more severely, they may also tend to perceive the natural world as just. The idea of a just nature can be traced back to the early reception of Gaia hypothesis (Lovelock, 1967; Lovelock \& Margulis, 1974) which states that the Earth's biosphere is a self-regulating, complex system that aims to maintain stability and sustainability by regulating physical and chemical processes. At first, the Gaia hypothesis was perceived as ideological rather than scientific, but the results of contemporary empirical research seem to be in line with the idea that the biosphere tends to maintain homeostasis at a planetary level. Although the original Gaia hypothesis does not assume that this system is purposeful or that its observed effects are 
intentional and planned (Lovelock, 1990), the idea that nature (Gaia) regulates physical processes to sustain life on Earth in general may be appealing because it offers an explanation of complex natural processes and as such may be perceived as a form of motivated cognition (cf. John, Kruglanski, Glaser, \& Sulloway, 2003). This idea of a just nature that is able to punish those who harm it may be especially appealing to people who identify themselves as caring for the natural environment, and for whom it is an important and valuable part of their selfconcept.

However, a consequence of holding such beliefs would be psychological distancing from those who are blamed for pollution of the natural environment or killing the endangered species for profit, that is, for violation of environmental sustainability. Therefore, those who attribute responsibility for the effects of the disasters to the victims and at the same time believe that the disaster is a justified reaction from nature may be less willing to offer help to human victims than to restore the natural environment. We hypothesize, therefore, that those who believe that nature is in fact just and able to withstand harmful human activity, and perceive victims of the natural disasters as responsible for their own harm, would be less prone to help them than the natural environment.

\section{Overview of Current Research}

We tested these hypotheses in a series of studies using a mixed-method approach. First, we analyzed spontaneous explanations of a natural disaster in Japan (tsunami wave in March 2011). Second, in a series of quantitative studies using correlational designs, we tested whether belief in a just nature was associated with a preference to reduce negative consequences regarding the natural environment rather than consequences for human victims in two different contexts (tsunami wave in Japan in 2011 and Hurricane Sandy in 2012) using two different dependent measures.

\section{Pre-study}

First, we decided to investigate whether individuals spontaneously express the belief in a just nature and to what extent these are held. The starting point for this research was the systematic monitoring of the Facebook profile of the Polish Greenpeace division in a month following the Fukushima disaster. We have analyzed discussions regarding the consequences of the tsunami wave in Japan in March 2011. Greenpeace is one of the most important and influential ecological organizations in the world. It has 2.9 million individual supporters, and its Polish division is one of the most active ecological organizations in the country ("40 lat Greenpeace," 2012). The Facebook profile allows its followers to actively comment on content provided by the organization. Five articles related to the Fukushima tragedy were identified in the studied period. They were commented on 84 times by 53 unique Facebook users. All comments submitted by Polish Greenpeace and other formal organizations were excluded from the analysis. 
Every comment was then coded separately in ATLAS.ti CAQDA software (Fielding, 2001; Friese, 2012) by two competent judges according to whether it expressed the belief that nature is just, that nature is able to repay the harm done to the natural environment, and/or has repaid the harm done to the natural environment in the case of Japan. Comments were categorized as reflecting a belief in a just nature if they included direct or presupposed statements that

- nature responds intentionally to harmful actions aimed at it, e.g., polluting the environment, killing wild animals, etc.;

- people or the governments are responsible for natural disasters occurring in their countries by their previous actions against nature.

The quotations that did not directly articulate such views but expressed open support for such statements formulated by other Facebook users were also categorized as reflecting beliefs in a just nature. The quotations referring to bad deeds of Japanese toward nature were also included in the analysis even if they did not contain an explicit causal link between past environmental damage and the Fukushima disaster. However, in the context of the Fukushima disaster the presupposition of those statements was that "Mother Nature" was responsible for harm to the Japanese. It is suggested by discourse analytics (Van Dijk, 1992, 2006) that references to out-group offences may serve as a justification for out-group harm and in-group violence. Seven quotations were identified by at least one of the judges. Representative statements are: "People have done so much harm to nature that she finally stopped taking blows and now fights back its oppressors"; "They should not have killed so many whales and dolphins." Inter-rater agreement measured by Cohen's $\kappa$ (Cohen, 1960; Hallgren, 2012) was .92.

Of all comments related to the Fukushima disaster identified on the Facebook forum, $8.33 \%$ referred to a belief in a just nature and $13.21 \%$ of active commentators directly expressed belief in a just nature.

The results of this pre-study are of course preliminary, and their generalizability is limited due to the small number of identified quotations and due to the specificity of their origin. However, they suggest that individuals, at least those actively interested in environmental issues, spontaneously express beliefs in a just nature as a way to explain natural disasters and their effects. In a series of quantitative studies presented in this article, we have tested whether holding such beliefs may be associated with the lower willingness to help human victims of natural disasters in contrast to the will to restore the natural environment.

\section{Study 1}

Method

\section{Participants and Procedure}

Participants were recruited via adverts published on various Polish websites devoted to ecology and on Facebook 9 days after the huge tsunami wave in Japan in March 
2011. Our Facebook adverts were targeted only at persons with a declared Polish nationality and with a declared interest related to at least one environmental issue (for example, ecology, environment protection, recycling, etc.). Adverts redirected respondents to an external webpage where the actual questionnaire was published. In total, 183 persons entered the study website, and of those 120 completed the survey. Of those 82 were men, 38 were women. The mean age of participants was 30.85 (standard deviation $[\mathrm{SD}]=10.24$ ) with median of 28 .

At the beginning of the study, participants were informed that in return for their time spent filling in the questionnaire, they would be able to indicate the fund for which the researchers would transfer a small sum of money (1 PLN per person). Then, they were asked to answer questions regarding their environmental identity, beliefs about nature, and demographics. At the end of the study, they were offered the opportunity to support either Japanese human victims via Polish Humanitarian Action, or the natural environment in Japan via the World Wildlife Fund (WWF). After the data were collected, we calculated the sums donated by participants to both funds and transferred 48 and 72 PLN to Polish Humanitarian Action and WWF, respectively.

\section{Measures}

\section{Pro-environmental Identity}

The strength of pro-environmental identification was measured using the threedimensional Scale of Social Identification by Cameron (2004) in Polish adaptation (Bilewicz \& Wójcik, 2010). The scale distinguishes between three dimensions of identity: centrality (importance of group membership), in-group affect (positive emotions about group membership), and in-group ties (strength of relations with other group members). ${ }^{1}$

\section{Environmental Concerns}

The Snelgar (2006) Scale of Environmental Concerns was used to measure the reasons for caring for the environment. The scale distinguishes three dimensions of environmental concern: egoistic (caring for environment due to self-interest), altruistic (caring for environment due to interest for other people and humanity), and biospheric (caring for environment due to interest for itself). ${ }^{2}$

\footnotetext{
${ }^{1}$ The theoretical factor analysis with Varimax rotation analysis yielded a three-factor solution: the first factor accounted for $42.61 \%$ of variance (Eigenvalue $=3.84$ ), second factor for $15.77 \%$ (Eigenvalue $=1.42$ ), and the third for $11.11 \%$ (Eigenvalue $=1.00$ ). They constituted three theoretically expected factors: centrality, ties, and affect, with the exception of one item expected to be associated with the affect scale, which loaded the centrality scale to a higher extent than the affect scale. The regression scores for factorial solutions were then saved and used as predictors in later steps of the analysis.

${ }^{2}$ To determine the structure of the data, a principal component analysis (with Varimax rotation) was performed. Three factors congruent with those theoretically expected were identified. The biospheric factor accounted for $36.31 \%$ of variance (Eigenvalue $=5.45$ ), the egocentric factor for $25.49 \%$ (Eigenvalue $=3.82$ ), and the altruistic for $23.77 \%$ (Eigenvalue $=3.57$ ). The regression scores for factorial solutions were used as predictors in later steps of the analysis.
} 


\section{Belief in a Just Nature}

Participants were asked to respond using a 7-point scale from 1 (definitely not) to 7 (definitely yes). The scale consisted of six items (see Table 1 for details). Principal component analysis (PCA) yielded a single factor solution accounting for $52.53 \%$ of variance, and Cronbach's $\alpha$ was .82. The regression score of factorial solution was used as a predictor in later steps of the analysis.

\section{Willingness to Donate to Humans Versus Nonhuman Environment}

Participants were asked to indicate to which fund they wished the small sum of money to be donated in return for participation in the survey. Each participant could choose between donation for Japanese human victims via Polish Humanitarian Action and donation for the natural environment in Japan via the WWF, and this behavioral measure was used as a binary dependent variable.

Results

A matrix of zero-order correlations was produced showing that belief in a just nature was significantly correlated with Biocentric Concerns as well as with centrality dimension of ecological identity. Only belief in a just nature was significantly

Table 1 Factor loading for principal component analysis and Cronbach's $\alpha$ for belief in a just nature scale (Studies 1-3)

\begin{tabular}{|c|c|c|c|}
\hline \multirow[t]{2}{*}{ Items } & \multicolumn{3}{|c|}{$\begin{array}{l}\text { Factor loadings } \\
\text { (PCA) in study }\end{array}$} \\
\hline & 1 & 2 & 3 \\
\hline $\begin{array}{l}\text { 1. The harm done to nature is returned } \\
\text { multiple times }\end{array}$ & .63 & .67 & .76 \\
\hline $\begin{array}{l}\text { 2. Natural disasters such as earthquakes, } \\
\text { hurricanes, and floods result from the } \\
\text { destruction of the environment }\end{array}$ & .77 & .69 & .66 \\
\hline $\begin{array}{l}\text { 3. Nature avenges the violation of its } \\
\text { balance }\end{array}$ & .72 & .82 & .70 \\
\hline $\begin{array}{l}\text { 4. People who agree to over-exploitation of } \\
\text { environmental resources are responsible } \\
\text { for natural disasters }\end{array}$ & .83 & .74 & .79 \\
\hline $\begin{array}{l}\text { 5. Any human interference in the natural } \\
\text { environment will meet with a response } 1 \\
\text { day }\end{array}$ & .53 & .61 & .62 \\
\hline $\begin{array}{l}\text { 6. The governments of countries that over- } \\
\text { exploit the environment are responsible } \\
\text { for natural disasters happening to those } \\
\text { countries }\end{array}$ & .83 & .70 & .82 \\
\hline Percent of variance explained & 52.53 & 50.15 & 52.94 \\
\hline Eigenvalue & 3.15 & 3.01 & 3.18 \\
\hline Cronbach's $\alpha$ & .82 & .80 & .82 \\
\hline
\end{tabular}


Table 2 Zero-order correlations between measured variables (Study 1)

\begin{tabular}{lrllllllll}
\hline Variables & 1 & 2 & 3 & 4 & 5 & 6 & 7 & 8 & 9 \\
\hline 1. Gender & & & & & & & & & \\
2. Age & .09 & & & & & & & & \\
3. Biospheric concern & -.05 & .01 & & & & & & & \\
4. Egocentric concern & -.13 & .02 & .00 & & & & & & \\
5. Altruistic concern & .14 & .08 & .00 & .00 & & & & & \\
6. Pro-environmental & -.08 & .04 & $.21 *$ & .05 & -.05 & & & & \\
$\quad$ identity: centrality & & & & & & & & & \\
7. Pro-environmental & .07 & .15 & $.19 *$ & -.11 & .02 & .00 & & & \\
$\quad$ identity: ties & & & & & & & & & \\
8. Pro-environmental & .11 & .12 & $-.22^{*}$ & -.02 & .13 & .00 & .00 & & \\
$\quad$ identity: affect & & & & & & & & & \\
9. Belief in a just nature & -.03 & .09 & $.18 *$ & .08 & .10 & $.40^{* *}$ & .02 & -.10 & \\
10. Donation choice & -.04 & -.04 & -.11 & -.12 & .16 & -.15 & -.04 & -.04 & $-.29 * *$ \\
\hline
\end{tabular}

Note the donation choice coded as 1 for WWF and 2 for Polish Humanitarian Action-Help Japan. Gender was coded as 1 for women and 2 for men

$* p<.05, * * p<.01$

correlated with a willingness to donate according to humans versus nonhuman environment (Table 2).

Logistic regression was performed with the preference to donate to humans versus nonhuman environment as the dependent variable. As presented in Table 3, age and gender entered in Step 1 were not significantly related to the donation choice. Adding to the regression equation, different forms of ecological identity as well as environmental concern as a block in Step 2 did not improve significantly the predictive power of the model $(\Delta-\operatorname{LL}(6)=11.18 ; p=.09)$ although the altruistic environmental concern was significantly related to the donation choice. Respondents whose environmental concern resulted from caring about other people gave their donation more willingly to Japanese human victims. Belief in a just nature added in Step 3 proved to be the strongest significant predictor of the donation choice. Introducing it to the logistic regression model significantly improved its predictive power $(\Delta-\mathrm{LL}(1)=8.99 ; p<.01)$. As predicted, people who believed that nature is just and that it can repay its harm-doers gave their donation more willingly to the WWF nature restoration program than to Japanese human victims.

\section{Discussion}

The results of Study 1 show that the level of belief in a just nature predicts the tendency to help either human victims of natural disasters or the nonhuman environment, at least among individuals who are interested in environmental issues. Those who share the belief in a just nature to a higher extent prefer to donate to the nonhuman environment rather than to human victims. Neither any form of environmental identity, nor biospheric or egocentric concerns predicted the donation choice. These relationships were examined in the context of the natural 
Table 3 Logistic regression for donation choice (Study 1)

\begin{tabular}{|c|c|c|c|c|c|}
\hline \multirow[t]{2}{*}{ Predictors } & \multirow{2}{*}{$-\mathrm{LL}(D)$} & \multirow[t]{2}{*}{$B(\mathrm{SE})$} & \multicolumn{3}{|c|}{$95 \%$ CI for odds ratio } \\
\hline & & & Lower & Odds ratio & Upper \\
\hline Step 1 & $161.15(.372)$ & & & & \\
\hline Age & & $-.00(.02)$ & .26 & .64 & 1.54 \\
\hline Gender & & $-.45(.45)$ & .96 & 1 & 1.04 \\
\hline Step 2 & $149.97\left(11.18^{\dagger}\right)$ & & & & \\
\hline Pro-environmental identity: centrality & & $-.03(.22)$ & 63 & .97 & 1.49 \\
\hline Pro-environmental identity: ties & & $-.08(.21)$ & 61 & .92 & 1.35 \\
\hline Pro-environmental identity: affect & & $-.28(.23)$ & .49 & .76 & 1.19 \\
\hline Egocentric concern & & $-.29(.22)$ & .49 & .75 & 1.15 \\
\hline Altruistic concern & & $.66(.28)^{*}$ & 1.12 & 1.87 & 3.34 \\
\hline Biospheric concern & & $-.27(.24)$ & .48 & .76 & 1.21 \\
\hline Step 3 & $140.98(8.99 * *)$ & & & & \\
\hline Belief in just nature & & $-.69(.25)^{* *}$ & .31 & .50 & .81 \\
\hline
\end{tabular}

Note The donation choice coded as 0 for WWF and 1 for Polish Humanitarian Action-Help Japan. Gender was coded as 1 for women and 2 for men. Step 1: H\&L $\chi^{2}=10.75$, ns; Cox and Snell $R^{2}=.00$; Nagelkerke $R^{2}=.00$; Step 2: H\&L $\chi^{2}=12.28$, ns; Cox and Snell $R^{2}=.09$; Nagelkerke $R^{2}=.12$; Step 3: H\&L $\chi^{2}=13.70, \mathrm{~ns}$; Cox and Snell $R^{2}=.16$; Nagelkerke $R^{2}=.21$

$\dagger p<.1, * p<.05, * * p<.01$

disaster following the tsunami wave in Japan in 2011, 10 days after the disaster when its effects were widely discussed in the media.

The correlational analysis supported the theoretical validity of belief in a just nature. As expected, belief in a just nature was higher among respondents who perceived their ecological identity as more central. The positive correlation between belief in a just nature and biospheric environmental concern may be interpreted thus: that people who believe that nature is just and that it responds actively against its harm-doers may be more concerned about the environment to avoid negative consequences to themselves.

Importantly, the measure used as a dependent variable was the actual behavior of donating to the preferred cause in a real-life situation, which increases ecological validity of the study and affects generalizability of results. It should be, however, noted that although ecologically valid, this was a forced-choice measure. Although in real-life situations people may actually choose the fund they support rather than divide money between different funds, this form of study, however, does not allow to refrain from donating to any cause. Therefore, in Study 2 the tendencies to donate to support human victims and the nonhuman environment were measured independently of each other.

The results of Study 1 were in line with the hypothesis predicting that individuals who believe in a just nature are less prone to care for human victims of natural disasters than for the nonhuman environment. However, this study fails to answer the question whether belief in a just nature predisposes individuals to blame the victims of natural disasters for its occurrence - and therefore to withdraw help-or whether it predisposes individuals to withdraw help from victims who are blamed for harming the environment. Study 2 was conducted to address this issue. 
Last, but not the least, participants of Study 1 were recruited from individuals interested in environmental issues, who cared for nature to a higher extent than an average person. The belief in a just nature may be stronger in that specific sample, as suggested also by significant positive correlation between environmental identity and belief in a just nature. As a consequence, the effects observed in Study 1 may be limited to that specific group. As we aim to predict the preference to donate to the environment or to human victims on a general level, rather than among specific groups, we used more general samples in the following studies.

\section{Study 2}

Study 2 was designed to probe relationships between BJN, responsibility attributed to victims of natural disasters, and the tendency to help human victims and the nonhuman environment. This study was also conducted in the context of the disaster in Japan in 2011 among students of social sciences. In Study 2, a different dependent variable was used to allow participants to support both human victims and nonhuman environment, and the perceived responsibility of victims was measured.

\section{Method}

\section{Participants and Procedure}

Participants were recruited from students of social sciences 2 weeks after the huge tsunami wave in Japan in March 2011. In total, 143 persons participated in the study; 74 were men, and 69 women. The mean age of the participants was $22.21(\mathrm{SD}=1.83)$.

\section{Measures}

\section{Pro-environmental Identity}

The strength of pro-environmental identification was measured using the same Scale of Social Identification as in Study 1. However, this time the results did not reflect the theoretical structure. Two factors emerged from Varimax analysis: the positive and negative pro-environmental identities, respectively, which were used in the following analyses. $^{3}$

\footnotetext{
3 The factor analysis with Varimax rotation yielded a two-factor solution: the first factor accounted for $45.27 \%$ of variance (Eigenvalue $=4.08$ ), and the second factor for $19.55 \%$ (Eigenvalue $=1.76$ ). The first factor was loaded primarily by seven out of nine items and consisted of items from all three theoretical dimensions of the scale. The second factor was loaded primarily by two scale items referring to negative emotions related to ecological identity. The regression scores for factorial solutions, named positive and negative pro-environmental identities, respectively, were then saved. The lack of reproduction of theoretically assumed factors (affect, ties, and centrality) may bethe result of differences between samples in Studies 1 and 2. The ecological identity may be more complex among people who perceive themselves as ecologists (Study 1). In Study 2, among ordinary students, the perception of ecological identity may not be as complex and be guided by more basic general positivity-negativity effect.
} 


\section{Perceived Japanese Responsibility for the Fukushima Catastrophe}

The scale was adapted from Zagefka et al.'s (2011) study. Participants were asked to what degree they think that Japanese people were responsible for the catastrophe. Participants were asked to respond using a 7-point scale from 1 (definitely not) to 7 (definitely yes). The scale consisted of four items (two reversed). PCA yielded a single factor solution accounting for $61.75 \%$ of variance.

\section{Belief in a Just Nature}

The same BJN scale was used as in Study 1. PCA yielded a single factor solution accounting for $50.15 \%$ of variance and Cronbach's $\alpha$ was .80 (see Table 1). The regression score for factorial solutions was used as predictor in later steps of the analysis.

\section{Environment Favoritism}

The participants were asked to respond as to the likelihood of their donating for Japanese human victims or for restoration of the natural environment in Japan. A 7 -point scale from 1 (definitely not) to 7 (definitely yes) was used. Then, the preference for the environment was created by subtracting the score for Japanese human victims from the score for restoration of the natural environment in Japan. The higher scores meant increased favoritism for the environment.

\section{Interest in Helping Japanese People and/or Japanese Environment}

At the end of questionnaire, two informational leaflets were attached: one with a web link to a webpage devoted to help to Japanese people and the second with a web link to a webpage devoted to the restoration of the Japanese natural environment. Respondents could take two, one, or none of the informational leaflets, and were thus categorized into four subgroups.

\section{Results}

A matrix of zero-order correlations was produced showing that belief in a just nature was significantly correlated with the positive environmental identity, but also with the perceived Japanese responsibility for the Fukushima accident. Again, belief in a just nature was the only variable that correlated significantly with environment favoritism (see Table 4).

In order to test the hypothesis postulating interaction between belief in a just nature and perceived responsibility of victims, hierarchical linear regression was employed using Hayes's (2012) computational procedure with environment favoritism as the dependent variable. As the pro-environmental identity was not a significant predictor of preference for the environment, and the data obtained in Study 2 did not reflect theoretical structure, it was not included in this analysis. Age 
Table 4 Zero-order correlations between measured variables in Study 2

\begin{tabular}{lrrrrrr}
\hline Variables & \multicolumn{1}{l}{ 1 } & 2 & 3 & 4 & 5 & 6 \\
\hline 1. Gender & & & & & & \\
2. Age & -.06 & & & & & \\
3. Pro-environmental identity: positive & .00 & -.03 & & & & \\
4. Pro-environmental identity: negative & .12 & -.07 & .00 & & & \\
5. Belief in just world & $-.18^{*}$ & -.13 & $.26^{* *}$ & -.08 & & \\
6. Perceived Japanese responsibility & -.02 & -.15 & .14 & .11 & $.51^{* *}$ & \\
7. Environment favoritism & -.03 & .03 & .05 & -.06 & $.17^{*}$ & .14 \\
\hline
\end{tabular}

Note gender was coded as 1 for women and 2 for men

$* p<.05, * * p<.01$

and gender, entered as a block in Step 1, were insignificantly related to environment favoritism. Adding to the regression equation, belief in a just nature in Step 2 improved significantly the predictive power of the model $\left(\Delta R^{2}=.03, p<.05\right)$. Belief in a just nature was related positively to environment favoritism. However, the effect proved to be insignificant after controlling for the perceived Japanese responsibility for the Fukushima accident in Step 3.

Finally, the interaction term between belief in a just nature and perceived Japanese responsibility, entered in Step 4, significantly increased the amount of variance explained by the model $\left(\Delta R^{2}=.03, F(1,130)=4.19, p<.05\right)$ (see Table 5). Thus, Japanese responsibility was a significant moderator of the relationship between belief in a just nature and environment favoritism. The significant interaction was further analyzed using the procedure proposed by Aiken and West (1991). One SD below and above the mean score on the perceived Japanese responsibility scale was used to plot the equations and to test the significance level of each simple slope. The unstandardized simple slope for respondents $1 \mathrm{SD}$ below the mean of perceived Japanese responsibility was -.03 $(p=.90)$, and the unstandardized simple slope for employees $1 \mathrm{SD}$ above the mean of Japanese responsibility was $.54(p<.05)$. As depicted in Fig. 1, belief in a just nature significantly predicted the level of environment favoritism only among those who attributed the responsibility to the victims of natural disaster.

Our alternative hypothesis stated that belief in a just nature may lead to attribution of responsibility to the victims of natural disasters and as a result decreases willingness to offer help to human victims. Therefore, we tested the possible mediation of attributed responsibility between belief in a just nature and environment favoritism. Mediation analysis was performed using the SPSS Hayes macro Process (2012). Bootstrapping (with 50,000 resamples) was used to build $95 \%$ confidence intervals (CIs). The point estimate for the indirect effect was .07; CIs included 0 ( $\mathrm{LL}=-.08$ to $\mathrm{UL}=.22)$, denoting nonsignificant indirect effect. Thus, the results of mediation analysis showed no significant indirect effect of belief in a just nature on environment favoritism. Taken together, these results suggest that belief in a just nature does not lead in itself to attribution of responsibility to the victims of natural disasters that would result in decreased willingness to help them, 
Table 5 Linear regression for environment favoritism (Study 2)

Note the belief in a just nature and Japanese responsibility were introduced into the equation as standardized regression scores from exploratory factor analysis. $\Delta R^{2}=.00, p=.89$ for Step 1 ; $\Delta R^{2}=.03, p<.05$ for Step 2; $\Delta R^{2}=.01, p=.43$ for Step 3; $\Delta R^{2}=.03, p<.05$ for Step 4 $* p<.05$

\begin{tabular}{llll}
\hline Variables & $B$ & $\operatorname{SE}_{B}$ & $\beta$ \\
& & $B$
\end{tabular}

Step 1

$\begin{array}{lrrr}\text { Gender } & -.08 & .27 & -.03 \\ \text { Age } & .03 & .07 & .03\end{array}$

Step 2

$\begin{array}{lllll}\text { Gender } & .02 & .28 & .01\end{array}$

Age

$\begin{array}{lll}.05 & .07 \quad .06\end{array}$

Belief in a just nature

$.29 .14 \quad .18 *$

Step 3

Gender

$\begin{array}{lll}.01 & .28 & .00\end{array}$

Age

$\begin{array}{lll}.06 & .07 \quad .07\end{array}$

Belief in a just nature

$.22 \quad .16 \quad .14$

Japanese responsibility

$.13 \quad .16 \quad .08$

Step 4

$\begin{array}{lllll}\text { Gender } & -.05 & .27 & -.01\end{array}$

Age

$\begin{array}{lll}.06 & .07 \quad .07\end{array}$

$\begin{array}{lllll}\text { Belief in a just nature } & .26 & .16 & .17\end{array}$

$\begin{array}{lllll}\text { Japanese responsibility } & .13 & .16 & .08\end{array}$

Belief in a just nature $\times$ Japanese $\quad .28 \quad .14 \quad .18^{*}$ responsibility

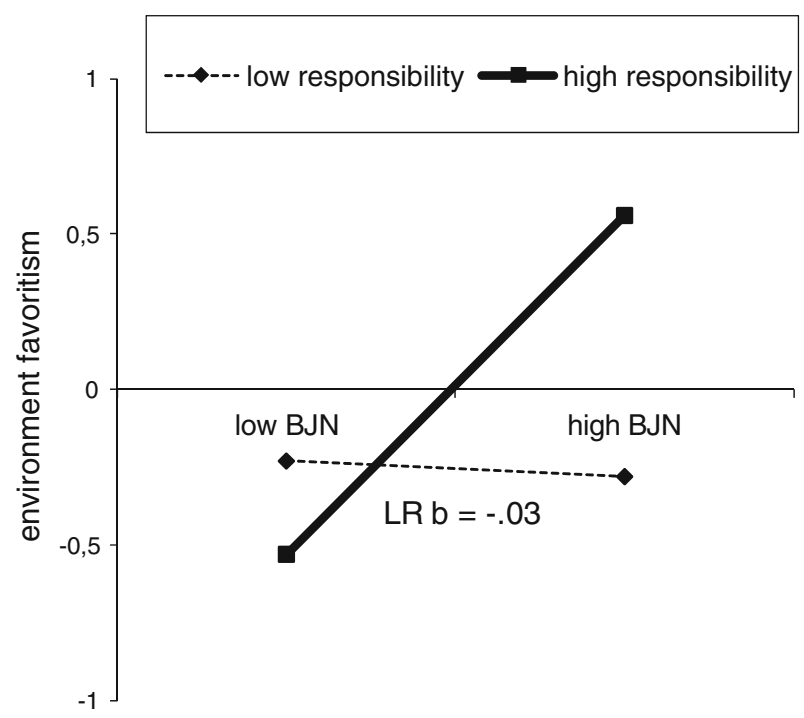

Fig. 1 Preference to help natural environment over human victims (Study 2)

but rather that belief in just a nature leads to decreased willingness to help the victims of natural disasters among those who attribute responsibility to victims for harming environment. 
In order to check whether the belief in a just nature would predict actual behavior, we conducted discriminatory analysis to differentiate between respondents who decided to take information about help, respectively, for Japanese people, Japanese nature, and both Japanese people and nature, and also those who took no information about possible help for Japan. The discriminant analysis with belief in a just nature as the only predictor was used for this purpose. The results of the analysis were insignificant. The discriminant function Eigenvalue was .02, canonical $R^{2}=.14 ; \Lambda=.98 ; \chi^{2}(3)=2.893 ; p=.41$. However, as presented in Table 6 , the function for the group centroid shows that the main differences are between the respondents who took only specific information about help possibilities for Japanese people or for Japanese nature. We repeated the analysis, trying to discriminate between those specific respondents' groups.

The discriminant function Eigenvalue was .145 , canonical $R^{2}=.36 ; \Lambda=.87$; $\chi^{2}(1)=3.054 ; p=.08$. The function at the centroid for the group of respondents who decided to take information only about help toward Japanese people was - 38 . The function at the centroid for the group of respondents who decided to take information only about help toward Japanese nature was .35. Although the results only approached significance, this suggests that belief in a just nature may differentiate people who prefer rather to help human victims than to restore the natural environment.

\section{Discussion}

The results of Study 2 confirmed the previous finding showing that belief in a just nature is associated with the preference to offer help to restore the natural environment rather than for human victims using a different dependent variable. Importantly, this study further develops this idea by showing that belief in a just nature decreases willingness to help the victims of natural disasters, but only among those who attribute responsibility to the victims for previous misdeeds.

It should be, however, noted that previous results were obtained in the same context of a natural disaster in Japan. However, any single disaster may provide a specific context. For example, in the case where the tsunami wave hit Japan (natural factor) and resulted in a disaster at the Fukushima Nuclear Power Plant, this disaster may be attributed to human activity. As a consequence, the effects observed in previous studies may result from the fact that this disaster was not perceived as a natural one, but rather was brought by humans on themselves. Therefore, we aimed to replicate the results in a different context.

Table 6 Function for the group centroid-BJN as the only predictor (Study 2)

\begin{tabular}{lcc}
\hline Groups & Values & $N$ \\
\hline Nothing & .03 & 98 \\
All & -.10 & 21 \\
Japanese people only & -.37 & 12 \\
Japanese nature only & .27 & 13 \\
\hline
\end{tabular}




\section{Study 3}

In Study 3, a different context was used to probe the relationships between belief in a just nature, attributed responsibility, and willingness to help human victims and restore the natural environment. This time we aimed to test these relationships a short time after Hurricane Sandy hit America in October 2012. This disaster had no after-effects that would be perceived as related to human activity and could be perceived as more disturbing than the hurricane itself.

This study was planned in an experimental design. Unfortunately, owing to problems with the web data-collection system, only parts of the planned questionnaire were administered to participants. Thus, the data were used as a replication of Study 1 to investigate whether the belief in a just nature predicts the preference to donate to the nonhuman environment than to human victims in a different context.

\section{Method}

\section{Participants and Procedure}

Participants were recruited from students of social sciences from 5 to 10 days after Hurricane Sandy hit the USA in late October 2012. The respondents received an e-mail with an invitation to participate in the research. In total, 158 persons entered and completed the study. Of those 32 were men, 126 were women. The mean age of participants was $23.36(\mathrm{SD}=4.96)$.

At the beginning of the study, participants were informed that in return for their time spent on filling in the questionnaire they would be able to indicate the fund for which the researchers would transfer a small sum of money (1 PLN per person). Then, they were asked to answer questions regarding their environmental identity, beliefs about nature, and demographics. At the end of the study, they were offered the opportunity to support either human victims or the natural environment. As the Polish media at the time reported mostly the damage caused by Hurricane Sandy to the USA, we offered participants the choice between a donation for human victims via Food Bank for New York City, or for restoring the natural environment in USA via North Shore Animal League America. After the data were collected, we calculated the sums donated by participants to both funds and transferred 80 and 75 PLN to Food Bank for New York City and North Shore Animal League America, respectively.

\section{Measures}

\section{Belief in a Just Nature}

The same BJN scale as that in Study 1 was used. PCA yielded a single factor solution accounting for $52.94 \%$ of variance and Cronbach's $\alpha$ was .82 (see Table 1 for details). The regression score for factorial solutions was used as the predictor in later steps of the analysis. 


\section{Willingness to Donate to Humans Versus Nonhuman Environment}

Participants were asked to indicate to which fund they wished to donate the small sum of money in return for participation in the survey. Each participant could choose between a donation for Hurricane Sandy victims via Food Bank for New York City and a donation for the natural environment in the USA via North Shore Animal League America, and this behavioral measure was used as a binary dependent variable. Overall, $56.5 \%$ participants chose Food Bank for New York City, while other $43.4 \%$ chose North Shore Animal League America.

\section{Results}

Logistic regression was performed with the preference to donate to humans versus nonhuman environment as the dependent variable. As presented in Table 7, age and gender entered in Step 1 were not significantly related to the donation choice. Adding to the regression equation, belief in a just nature improved significantly the predictive power of the model $(\Delta-\mathrm{LL}(1)=3.98 ; p<.05)$. The respondents with a higher belief in a just nature donated more willingly to restore the natural environment than they did to support human victims of Hurricane Sandy.

\section{General Discussion}

The series of studies presented here investigated the role of belief in a just nature in shaping helping intentions and helping behavior toward victims of natural disasters. The results of the pre-study in which the discourse over the natural catastrophe followed by the nuclear power plant disaster was analyzed (case of tsunami wave in Japan in 2011) showed that individuals spontaneously use the concept of a just nature to explain the natural disaster and its effects, especially on human victims. The results of a series of quantitative studies conducted in the context of actual

Table 7 Logistic regression for donation choice (Study 3)

\begin{tabular}{|c|c|c|c|c|c|}
\hline \multirow[t]{2}{*}{ Predictors } & \multirow[t]{2}{*}{$-\mathrm{LL}(D)$} & \multirow[t]{2}{*}{$B(\mathrm{SE})$} & \multicolumn{3}{|c|}{$95 \%$ CI for odds ratio } \\
\hline & & & Lower & Odds ratio & Upper \\
\hline Step 1 & $212.53(.86)$ & & & & \\
\hline Age & & $-.02(.04)$ & .91 & .98 & 1.05 \\
\hline Gender & & $.10(.41)$ & .49 & 1.10 & 2.47 \\
\hline Step 2 & $208.55(3.98 * *)$ & & & & \\
\hline Belief in a just nature & & $-.34(.17)^{*}$ & .51 & .72 & 1.00 \\
\hline
\end{tabular}

Note the donation choice coded as 0 for North Shore Animal League America and 1 for Food Bank for New York City. Gender was coded as 1 for women and 2 for men. Step 1: H\&L $\chi^{2}=5.40$, ns; Cox and Snell $R^{2}=.01$; Nagelkerke $R^{2}=.01$; Step 2: H\&L $\chi^{2}=10.14$, ns; Cox and Snell $R^{2}=.03$; Nagelkerke $R^{2}=.04$

$* p=.05, * * p<.05$ 
natural disasters (in Japan in 2011 and in the USA in 2012) showed that these beliefs have an impact on help aimed at mitigating the negative effects of natural disasters. Individuals who were more prone to the belief that nature is able to repay the harm done to the natural environment were also less likely to help human victims of natural disasters than they were to reduce the negative consequences for the natural environment. Belief in a just nature was demonstrated to affect helping intentions, but importantly also actual behavior. In Study 1, the belief in a just nature was associated with the preference to help the nonhuman victims of Japan's tsunami wave rather than the human victims, and in Study 3 participants who more strongly believed in a just nature preferred to give donations for restoring the natural environment rather than reduce the suffering of American human victims. The results of Study 2 extended these results by showing that belief in a just nature predicted environment favoritism only among those who attributed responsibility to the victims for previous harms. Importantly, in two of the studies, the actual behavior was measured, and all of the studies were conducted in real-life contexts. Moreover, the studies were conducted in the context of two different catastrophes, differing in the extent to which their causes may be attributed to human activity, using different operationalizations, and among different groups of respondents (environmental activists and students). All these factors increase ecological validity and generalizability of results.

It should be , however, noted that, although we used two different contexts to probe these effects (one natural disaster, and one natural disaster followed by nuclear power plant disaster), in both cases, the countries affected by natural disasters were developed countries, responsible to a high degree for polluting the natural environment (Ewing et al., 2010). However, in the case of disasters in developing countries, which may not be perceived as harming the environment, responsibility for natural disasters may be attributed to other groups (developed countries), in which case, belief in a just nature may not affect the tendency to help human victims. This idea is in accordance with the results of Study 2, in which belief in a just nature was associated with the lowered tendency to help human victims only among those who attributed responsibility to victims. Therefore, in future research, the effect of belief in a just nature on helping should be investigated across different socioeconomic contexts, and the role of perceptions of countries as polluting natural environments should be taken into account. As these were the first studies regarding the concept of belief in a just nature, we aimed at increasing ecological validity, and we therefore conducted the studies presented here in the context of actual disasters. However, in the future studies, the context may also be manipulated, and this may be achieved by manipulating the name of the country in which the disaster occurred. As people in general may not be aware even of the indexes used to compare the level of pollution (Carbon Trust, 2012), even the information on the level of natural environment pollution in the country in which disasters occurred may be manipulated, which would allow us to use real-life contexts.

Although there are clear limitations to any individual study reported here, we aim to address these problems in other studies. Although the dependent variable in Studies 1 and 3 was a forced-choice measure-that is, if participants chose one 
fund, they could not choose another-in Study 2, the dependent variable was measured using Likert-type scales. Similarly, the dependent measure in Study 2 was declarative, but it was behavioral in Studies 1 and 3. In Studies 1 and 3, we used the names of actual funds that at the time collected money to reduce the negative effects of the catastrophes. On the one hand, it enhanced ecological validity, but on the other hand, some participants might have been biased against or in favor of some existing organizations. Therefore, in Study 2, a different dependent measure was used, which did not involve any names of actual funds. In the pre-study and Study 1, we analyzed data obtained from samples of persons especially interested in environmental issues, but participants in Studies 2 and 3 represented more general samples. Finally, we aimed at measuring both induced and spontaneous expression of beliefs in a just nature in two different real-life contexts.

Finally, it has to be noted that although the results were significant, the effects were moderate in magnitude. Nevertheless, the predictive power of belief in a just nature in explaining environment favoritism increased when responsibility was more strongly attributed to the victims. This result suggest new directions in further research on the effects of belief in a just nature. The attribution of responsibility may be affected not only by factors such as perception of the country as economically growing at the expense of the natural environment, but also by media coverage that may strongly affect the impressions of the victims of disasters. Importantly, future research should also be aimed at mitigating the negative effects of belief in a just nature on willingness to help human victims of natural disasters. This may be achieved either by experimentally attenuating the belief in a just nature-for example, by presenting participants with the scientific arguments or by showing examples evidencing the lack of natural justice - or by decreasing the level of responsibility attributed to the victims, for example, by media messages, as already suggested.

More practically, the results of the studies presented here may also help us develop strategies for advertising aimed at potential donors, and may give practical guidance to NGOs and charity funds. These results show that although some donors may be reluctant to donate to human victims, they may nevertheless be willing to donate for the restoration of the natural environment. Advertising the opportunity to donate to alternative causes more widely may increase international aid offered to countries which have suffered from natural disasters.

Acknowledgments This research was supported by a grant from the Polish National Science Centre (DEC-2011/03/N/HS6/03573).

Open Access This article is distributed under the terms of the Creative Commons Attribution License which permits any use, distribution, and reproduction in any medium, provided the original author(s) and the source are credited.

\section{References}

Aiken, L. S., \& West, S. G. (1991). Multiple regression: Testing and interpreting interactions. Newbury Park, CA: Sage.

Bilewicz, M., \& Wójcik, A. (2010). Does identification predict community involvement? Exploring consequences of social identification among the Jewish minority in Poland. Journal of Community and Applied Social Psychology, 20(1), 72-79. doi:10.1002/casp.1012. 
Bryan, J. H., \& Test, M. A. (1967). Models and helping: Naturalistic studies in aiding behavior. Journal of Personality and Social Psychology, 6, 400-407.

Cameron, J. (2004). A three-factor model of social identity. Self and Identity, 3, 239-262.

Carbon Trust. (2012). A global survey of young adult's perceptions of carbon and climate change. Retrieved May 9, 2013, from http://www.carbontrust.com/media/56157/carbon_trust_survey_ young_adults_perceptions_carbon_and_climate_change.pdf.

Cohen, J. (1960). A coefficient of agreement for nominal scales. Educational and Psychological Measurement, 20(1), 37-46. doi:10.1177/001316446002000104.

Ewing, B., Moore, D., Goldfinger, S., Oursler, A., Reed, A., \& Wackernagel, M. (2010). The ecological footprint atlas 2010. Oakland, CA: Global Footprint Network.

Fielding, N. (2001). Computer applications in qualitative research. In W. P. Atkinson, A. Coffey, S. Delamont, J. Lofland, \& L. Lofland (Eds.), Handbook of ethnography (1st ed., pp. 453-467). London: Sage Publication.

Friese, S. (2012). ATLAS.ti 7 user manual. Berlin: ATLAS.ti Scientific Software Development GmbH.

Furnham, A. (2003). Belief in a just world: Research progress over the past decade. Personality and Individual Differences, 34, 795-817.

Hafer, C. L. (2000). Do innocent victims threaten the belief in a just world? Evidence from a modified Stroop task. Journal of Personality and Social Psychology, 79(2), 165-173.

Hallgren, K. (2012). Computing inter-rater reliability for observational data: An overview and tutorial. Tutorials in Quantitative Methods for Psychology, 8(1), 23-34.

Harvey, P., Stoddard, A., Harmer, A., \& Taylor, G. (2010). The state of the humanitarian system: Assessing performance and progress a pilot study. London: Overseas Development Institute.

Hayes, A. F. (2012). PROCESS: A versatile computational tool for observed variable mediation, moderation, and conditional process modeling [White paper]. http://www.afhayes.com/public/ process2012.pdf.

Ickes, W., \& Kidd, R. (1976). An attributional analysis of helping behavior. In J. Harvey, W. Ickes, \& R. Kidd (Eds.), New directions in attribution research (Vol. 1, pp. 311-334). Hillsdale, NJ: Erlbaum.

John, J., Kruglanski, A., Glaser, J., \& Sulloway, F. (2003). Political conservatism as motivated social cognition. Psychological Bulletin, 129(3), 339-375.

40 lat Greenpeace. (2012). Retrieved January 11, 2013, from http://www.greenpeace.org/poland/pl/o-nas/ 40-lat-organizacji-greenpeace/.

Lerner, M. J. (1980). The belief in a just world: A fundamental delusion. New York: Plenum.

Lerner, M. J., \& Miller, D. T. (1978). Just world research and the attribution process: Looking back and ahead. Psychological Bulletin, 85(5), 1030-1051.

Lovelock, J. E. (1967). Gaia as seen through the atmosphere. Atmospheric Environment, 6(8), 579-580. doi:10.1016/0004-6981(72)90076-5.

Lovelock, J. E. (1990). Hands up for the Gaia hypothesis. Nature, 344(6262), 100-102. doi:10.1038/ $344100 \mathrm{a} 0$.

Lovelock, J. E., \& Margulis, L. (1974). Atmospheric homeostasis by and for the biosphere: The Gaia hypothesis. Tellus, 26(1-2), 2-10.

Meyer, J. P., \& Mulherin, A. (1980). From attribution to helping: An analysis of the mediating effects of affect and expectancy. Journal of Personality and Social Psychology, 39(2), 201-210.

Piliavin, I. M., Rodin, J., \& Piliavin, J. A. (1969). Good samaritanism: An underground phenomenon? Journal of Personality and Social Psychology, 13, 289-299.

Poole, L., \& Walmsley, L. (2012). GHA report 2012. Somerset: Development Initiatives.

Skitka, L. J. (1999). Ideological and attributional boundaries on public compassion: Reactions to individuals and communities affected by a natural disaster. Personality and Social Psychology Bulletin, 25(7), 793-808. doi:10.1177/0146167299025007003.

Snelgar, R. S. (2006). Egoistic, altruistic, and biospheric environmental concerns: Measurement and structure. Journal of Environmental Psychology, 26, 87-99.

Van Dijk, T. A. (1992). Discourse and the denial of racism. Discourse and Society, 3(1), 87-118. doi:10. $1177 / 0957926592003001005$.

Van Dijk, T. A. (2006). Discourse and manipulation. Discourse and Society, 17(3), 359-383. doi:10. $1177 / 0957926506060250$.

van Leeuwen, E. (2007). Restoring identity through outgroup helping: Beliefs about international aid in response to the December 2004 tsunami. European Journal of Social Psychology, 37, 661-671.

Weiner, B. (1980). A cognitive (attribution)-emotion-action model of motivated behavior: An analysis of judgments of help-giving. Journal of Personality and Social Psychology, 39, 186-200. 
West, S. G., Whitney, G., \& Schnedler, R. (1975). Helping of a motorist in distress: The effects of sex, race, and neighborhood. Journal of Personality and Social Psychology, 31, 691-698.

Zagefka, H., Noor, M., Brown, R., Randsley de Moura, G. R., \& Hopthrow, T. (2011). Donating to disaster victims: Responses to natural and humanly caused events. European Journal of Social Psychology, 41(3), 353-363. doi:10.1002/ejsp.781. 